\title{
ON-LINE IDENTIFICATION OF SIMULATION EXAMPLES FOR FORGETTING METHODS TO TRACK TIME VARYING PARAMETERS USING THE ALTERNATIVE COVARIANCE MATRIX IN MATLAB
}

\author{
Ing. Ján VACHÁLEK, PhD.* \\ * Institute of Automation, Measurement and Applied Informatics \\ Faculty of Mechanical Engineering \\ Slovak University of Technology in Bratislava \\ Námestie Slobody 1, 81231 Bratislava 1 \\ jan.vachalek@stuba.sk
}

\begin{abstract}
The paper compares the abilities of forgetting methods to track time varying parameters of two different simulated models with different types of excitation. The observed parameters in the simulations are the integral sum of the Euclidean norm, deviation of the parameter estimates from their true values and a selected band prediction error count. As supplementary information, we observe the eigenvalues of the covariance matrix. In the paper we used a modified method of Regularized Exponential Forgetting with Alternative Covariance Matrix (REFACM) along with Directional Forgetting (DF) and three standard regularized methods.
\end{abstract}

KEYWORDS: online identification, time varying parameters, covariance matrix, forgetting

\section{INTRODUCTION}

This paper is devoted to online identification methods and their possible practical application along with adaptive control; while monitoring long-term, time operation of variant dynamic systems. An emphasis is set on long-term operation and consequently the working mechanism with non-informative data. The process of algorithm realization is also elaborated. Online identification methods are explored, where non-informative data that could possibly destabilize numerical computation of the identified system parameters is weighted by the chosen method to ensure ,forgetting". The contributions in this paper lay within two newly created algorithms and their modifications for online identification; based on the technique for utilizing an alternative covariance matrix. All algorithms are verified by simulations in Matlab Simulink software environment. Finally, the results obtained through the simulation algorithms mentioned in the article are compared to other commonly used algorithms.

\section{PROBLEM STATEMENT}

Let as consider a stochastic system in which observations are made at discrete time instants $\mathrm{k}=1,2 \ldots$. A directly manipulated input $\mathrm{u}_{\mathrm{k}}$ and an indirectly affected output $\mathrm{y}_{\mathrm{k}}$ (both possibly multivariate) can be distinguished in the data pair $d_{k}=\left(u_{k}, y_{k}\right)$. The collection of all data observed in the system up to time $t$ is denoted by $D_{t}=\left(d_{1}, d_{2}, \ldots . d_{t}\right)$. The dependence of a new pair of data $\left(\mathrm{u}_{\mathrm{k}}, \mathrm{y}_{\mathrm{k}}\right)$ on previous observations $\mathrm{D}_{\mathrm{k}-1}$ can be described by a conditional probability density function (p.d.f) with the following structure

$$
p\left(y_{k}, u_{k} \mid D_{k-1}, \theta_{k}\right)=p\left(y_{k} \mid u_{k}, D_{k-1}, \theta_{k}\right) p\left(u_{k} \mid D_{k-1}\right)
$$


Incomplete knowledge of the system behavior is expressed through a vector of unknown time varying parameters $\theta_{\mathrm{k}} \in \theta$. Note that the input generator described by the second term does not depend on these parameters directly, it is expected to utilize only prior information and information contained in observed data. These techniques are used in Regularized Exponential Forgetting (REF) and Stabilized Linear Forgetting (SLF).

\section{REF AND SLF TECHNIQUE}

Suppose that no explicit model of parameter changes is known. Yet, we can quantify our prior information (and possibly information taken from data already available) by introducing an alternative probability density function (p.d.f.) $\mathrm{p}^{*}\left(\theta_{\mathrm{k}+1} / \mathrm{D}_{\mathrm{k}}\right)$. The problem is then to construct a p.d.f. $p\left(\theta_{k+1} / D_{k}\right)$ based on two hypotheses described by the p.d.f. $p\left(\theta_{k} / D_{k}\right)$ (the case of no parameter changes) and the alternative p.d.f. $\mathrm{p}^{*}\left(\theta_{\mathrm{k}+1} / \mathrm{D}_{\mathrm{k}}\right)$ (the case of worst expected changes). For simplicity in this section we will use the notation $p_{0}(\theta), p_{1}(\theta)$ a $p^{*}(\theta)$ for the posterior, alternative and resulting p.d.f.'s, respectively. In [3], are formulated the task of choosing $\mathrm{p}^{*}$ given $\mathrm{p}_{0}$ and $\mathrm{p}_{1}$ as a Bayesian decision making problem. A short review of their solutions can be expressed: Let,

$$
p_{\hat{\theta}, P}=\frac{1}{\sqrt{2 \Pi}}|P|^{-\frac{1}{2}} \exp \left(-\frac{1}{2}(\theta-\hat{\theta})^{\prime} P^{-1}(\theta-\hat{\theta})\right)
$$

where $\widehat{\theta}$ and $\mathrm{P}$ denote the mean and covariance of a particular p.d.f., then the following solutions show:

$$
\begin{aligned}
& \mathrm{EF}: \\
& \widehat{\theta}^{*}=\hat{\theta}_{0}, P^{*-1}=\lambda P_{0}^{-1}+(1-\lambda) P_{1}^{-1} \\
& \mathrm{LF}: \\
& \hat{\theta}^{*}=\hat{\theta}_{0}, P^{*}=\lambda P_{0}+(1-\lambda) P_{1}
\end{aligned}
$$

Let's consider the model of the system with time varying parameters $\theta_{\mathrm{k}}$, see [3]. In order to be able to track parameter variations we complement the standard recursive last square (RLS) algorithm by exponential or linear forgetting according to (3) or (4) respectively. In addition the alternative mean is set equal to posterior mean $\widehat{\theta}_{\mathrm{k}+1 \mid \mathrm{k}}^{\mathrm{alt}}=\widehat{\theta}_{\mathrm{k} \mid \mathrm{k}}$ and for simplicity the alternative covariance is set equal to the prior covariance $\mathrm{P}_{\mathrm{k}+1 \mid \mathrm{k}}^{\text {alt }}=\mathrm{P}_{1,0}=\mathrm{Q}$. With this choice we can use a general forgetting algorithm with the following choice of forgetting operator

$$
F\left\{P_{k \mid k}, Q\right\}=\left[\lambda \quad P_{k \mid k}^{-1}+(1-\lambda) Q^{-1}\right]^{-1}
$$

which construct the harmonic mean for REF and

$$
F\left\{P_{k \mid k}, Q\right\}=\lambda \quad P_{k \mid k}+(1-\lambda) Q
$$

Constructs the arithmetic mean for SLF. In both cases the prior covariance matrix Q isn't forgotten and is repeatedly taken into account for every step $\mathrm{k}$ seen in [1].

\section{AUGMENTING REF WITH ACM}

The involved REF augmentation considers addition and keeping the initial information in Alternative Covariance Matrix (ACM) form, see [2]. The augmentation is based on the modified 
Dyadic reduction algorithm, where instead of adding a-priori covariance matrix Q, ACM is computed at each step. ACM is stabilizing the evolution of matrix $\mathrm{P}(0)$ after the recursive update. This operation is necessary for the REF algorithms to be augmented by the stabilization component in ACM form. The aforementioned stabilization component prevents the destabilization of the original algorithms at long running applications; when slow time changes are to be expected in the observed parameters in relation to the sampling period. The modified algorithm REF augmented with ACM is termed REFACM.

\section{METHODOLOGY FOR THE VERIFICATION OF THE SIMULATIONAL ALGORITHM}

Two different models were created in the verification of properties (for the introduced algorithms) in the observation of time variant parameters of dynamic systems.. These two models (model no. 1. and no. 2.) have a different approach to input excitation (input signal generator A and B). Algorithm quality has been compared through the use of DF, which is considered to be the standard in the field. The Praly Forgetting (PF) algorithm featured in [4] has also been considered, using the weighted covariance matrix P. All algorithms were subject to the same test with identical length using the two featured models.

All results were graphically evaluated, and analyzed in a table where algorithm quality has been shown numerically through parameters IS and PE.

\section{Description of model no. 1 and no. 2}

In the case of model 1., a second order model is considered with external disturbance $\mathrm{v}_{(\mathrm{t})}$ according to:

$$
y_{k}=\sum_{i=1}^{2} a_{i} y_{k-i}+\sum_{i=0}^{2} b_{i} u_{k-i}+\sum_{i=0}^{2} d_{i} v_{k-i}+e_{k}, e_{k} \approx N\left(0, \sigma^{2}\right)
$$

The values of constant parameters are given by: $\mathrm{a}_{2}=-0.9, \mathrm{~b}_{0}=0.5, \mathrm{~b}_{1}=-0.25, \mathrm{~b}_{2}=0.1, \mathrm{~d}_{1}$ $=0.8, \mathrm{~d}_{2}=0.2$ and $\sigma=0.1$.

The time variant parameter has been chosen as $\mathrm{a}_{(1)}=0.98$, which has been kept constant for half of the $n$ simulation steps, then at time $t=n / 2$ its value is changed to $a_{(1)}=-0.98$. The outside disturbance has been simulated as a square signal periodically changing its value from +1 to -1 every 100 simulation steps. The identification has been made difficult mainly by the rare occurrence of disturbances, which contain minimal information about the parameter $\mathrm{d}_{(\mathrm{i})}$.

For the needs of the simulation, two input signal generators have been assumed:

- Input signal generator A: discrete white noise generator

- Input signal generator B: input signal generated using the following equation: $u_{k}^{*}=0.8 u_{k-1}^{*}+0.2 u_{k}$, where $\mathrm{u}_{\mathrm{k}}$ is normally distributed white noise and $\mathrm{u}^{*}{ }_{\mathrm{k}-1}$ is the previous input value. For model no. 2. only one change has been realized in comparison to model no. 1. This has been carried out by altering the time variant parameter $\mathrm{a}_{(1, \mathrm{k})}=0.98 \cos (2 \pi \mathrm{k} / 250)$. In this case, two different input generators were considered as well:

- Input signal generator A: discrete white noise generator

- Input signal generator B: input signal generated similarly to model no 1 ., where $\mathrm{u}_{(\mathrm{k})}$ has been chosen only from the interval $\mathrm{u}_{(\mathrm{k})} \sim(0.5,1)$.

\section{VERIFICATION - MATLAB SIMULINK}


From the previously mentioned algorithms DF has been chosen along with an additional three normalized methods: REF, SLF and PF. For the simulation verification a set of S-Function libraries has been created along with a common universal user interface. This interface allows the user to select input data, simulated the model and observed algorithm. The output of the discussed simulations is a graphical representation of the observed parameters along with a data file containing the results for the following analysis. Integral sum (IS) of the Euclidian norm of parameter error and prediction error PE has been shown, which is the amount exceeded by the interval $\pm 3 \sigma^{2}$. The simulation experiments will be marked by the character pair XY, where $\mathrm{X}$ is the number of the utilized model (no. 1 or no. 2) and Y represents the generator utilized (A or B).

\section{EVALUATION OF SIMULATION RESULTS}

This section shows all results in table form. For the detailed description of the algorithm behaviour during the simulations with different lengths (simulations lasting $\mathrm{n}=6000,12000$ and 120 000) have been evaluated as shown in Tables (1 to 3). It is clear in Table (2); that using a simulation length of $n=12000$ steps artefacts of long lasting runs already start appearing. The result is the confirmation of REFACM algorithm quality in comparison to REF, which in case 1A achieved better results than REF. Algorithm PF also achieved excellent results. The data featured in Table (3) fully confirm the previous considerations of the REFACM algorithm quality. It is clear that ACM behaves as if a constraint has been enforced on parameter trending, which also implies the improvement of IS parameters in comparison to the results achieved by REF. The convergence of the REF covariance matrix is faster and finite in contrast to REFACM, where the convergence is slower and also the addition of excited ACM cannot be finite. The achieved simulation results and REFACM algorithm behaviour at 6000 and 120000 simulation steps, show that as the running length increases the quality improves in contrast to REF, see Figure 1. In Table (4) we have shown the influence of weighting factor $\lambda$ to the quality of REFACM algorithms. Best results in simulations were observed with $\lambda=0.8$.

\begin{tabular}{|l|l|l|l|l|}
\hline 6 000 steps & \multicolumn{1}{|c|}{$\mathbf{1 A}$} & \multicolumn{1}{c|}{$\mathbf{1 B}$} & \multicolumn{1}{c|}{ 2A } & \multicolumn{1}{c|}{ 2B } \\
\hline DF & IS $=356,6$ & IS $=957,3$ & IS $=3499,4$ & IS $=4016,0$ \\
\hline & $\mathrm{PE}=130$ & $\mathrm{PE}=131$ & $\mathrm{PE}=1723$ & $\mathrm{PE}=717$ \\
\hline SLF & $\mathrm{IS}=153,4$ & $\mathrm{IS}=208,6$ & $\mathrm{IS}=928,5$ & $\mathrm{IS}=2683,3$ \\
\hline & $\mathrm{PE}=18$ & $\mathrm{PE}=12$ & $\mathrm{PE}=210$ & $\mathrm{PE}=131$ \\
\hline REF & $\mathrm{IS}=118,3$ & $\mathrm{IS}=120,3$ & $\mathrm{IS}=740,9$ & $\mathrm{IS}=1336,7$ \\
\hline & $\mathrm{PE}=18$ & $\mathrm{PE}=12$ & $\mathrm{PE}=174$ & $\mathrm{PE}=103$ \\
\hline PF & $\mathrm{IS}=125,9$ & $\mathrm{IS}=114,4$ & $\mathrm{IS}=921,9$ & $\mathrm{IS}=1807,2$ \\
\hline & $\mathrm{PE}=23$ & $\mathrm{PE}=13$ & $\mathrm{PE}=197$ & $\mathrm{PE}=173$ \\
\hline REFACM & $\mathrm{IS}=127,4$ & $\mathrm{IS}=177,8$ & $\mathrm{IS}=963,8$ & $\mathrm{IS}=1985,1$ \\
\hline & $\mathrm{PE}=27$ & $\mathrm{PE}=34$ & $\mathrm{PE}=239$ & $\mathrm{PE}=166$ \\
\hline
\end{tabular}

Tab. 1 - Simulation length 6000 steps 


\begin{tabular}{|l|l|l|l|l|}
\hline 12 000 steps & \multicolumn{1}{|c|}{ 1A } & \multicolumn{1}{|c|}{ 1B } & \multicolumn{1}{c|}{ 2A } & \multicolumn{1}{c|}{ 2B } \\
\hline DF & IS $=645,7$ & $\mathrm{IS}=1604,6$ & $\mathrm{IS}=6701,0$ & $\mathrm{IS}=7474,5$ \\
\hline & $\mathrm{PE}=253$ & $\mathrm{PE}=214$ & $\mathrm{PE}=3892$ & $\mathrm{PE}=1488$ \\
\hline SLF & $\mathrm{IS}=219,2$ & $\mathrm{IS}=257,5$ & $\mathrm{IS}=1533,4$ & $\mathrm{IS}=3589,9$ \\
\hline & $\mathrm{PE}=18$ & $\mathrm{PE}=13$ & $\mathrm{PE}=363$ & $\mathrm{PE}=179$ \\
\hline REF & $\mathrm{IS}=168,9$ & $\mathrm{IS}=253,9$ & $\mathrm{IS}=1457,2$ & $\mathrm{IS}=2525,3$ \\
\hline & $\mathrm{PE}=13$ & $\mathrm{PE}=14$ & $\mathrm{PE}=351$ & $\mathrm{PE}=188$ \\
\hline PF & $\mathrm{IS}=103,5$ & $\mathrm{IS}=165,4$ & $\mathrm{IS}=1760,8$ & $\mathrm{IS}=3210,8$ \\
\hline & $\mathrm{PE}=14$ & $\mathrm{PE}=15$ & $\mathrm{PE}=379$ & $\mathrm{PE}=355$ \\
\hline REFACM & $\mathrm{IS}=162,9$ & $\mathrm{IS}=296,3$ & $\mathrm{IS}=1844,9$ & $\mathrm{IS}=4507,3$ \\
\hline & $\mathrm{PE}=21$ & $\mathrm{PE}=31$ & $\mathrm{PE}=654$ & $\mathrm{PE}=439$ \\
\hline
\end{tabular}

Tab. 2 - Simulation length 12000 steps

\begin{tabular}{|l|l|l|}
\hline 120 000 steps & \multicolumn{1}{|c|}{ REF } & REFACM \\
\hline 1A & IS $=1035,4$ & IS $=880,8$ \\
\hline & PE $=17$ & $\mathrm{PE}=51$ \\
\hline 1B & IS $=3419,5$ & $\mathrm{IS}=2963,7$ \\
\hline & $\mathrm{PE}=12$ & $\mathrm{PE}=29$ \\
\hline
\end{tabular}

Tab. 3 - Simulation length 120000 steps only for best performing algorithms REF and REFACM

\begin{tabular}{|l|l|l|l|}
\hline REFACM & $\boldsymbol{\lambda}=\mathbf{0 . 8}$ & \multicolumn{1}{|c|}{$\mathbf{0 . 5}$} & $\boldsymbol{\lambda}=\mathbf{0 . 2}$ \\
\hline 1A & IS $=127,4$ & IS $=164,2$ & IS $=182,8$ \\
\hline & $\mathrm{PE}=27$ & $\mathrm{PE}=34$ & $\mathrm{PE}=48$ \\
\hline $\mathbf{1 B}$ & $\mathrm{IS}=177,8$ & $\mathrm{IS}=298,9$ & $\mathrm{IS}=496,9$ \\
\hline & $\mathrm{PE}=34$ & $\mathrm{PE}=50$ & $\mathrm{PE}=94$ \\
\hline $\mathbf{2 A}$ & $\mathrm{IS}=963,6$ & $\mathrm{IS}=870,1$ & $\mathrm{IS}=1031,6$ \\
\hline & $\mathrm{PE}=239$ & $\mathrm{PE}=289$ & $\mathrm{PE}=327$ \\
\hline 2B & $\mathrm{IS}=1985,1$ & $\mathrm{IS}=1520,0$ & $\mathrm{IS}=1732,8$ \\
\hline & $\mathrm{PE}=166$ & $\mathrm{PE}=145$ & $\mathrm{PE}=167$ \\
\hline
\end{tabular}

Tab. 4 - Influence of weighing factor $\lambda$, for REFACM algorithm 
SCIENTIFIC PROCEEDINGS 2011, Faculty of Mechanical Engineering, STU in Bratislava Vol. 19, 2011, pp. 94-99, DOI: 10.2478/v10228-011-0016-X

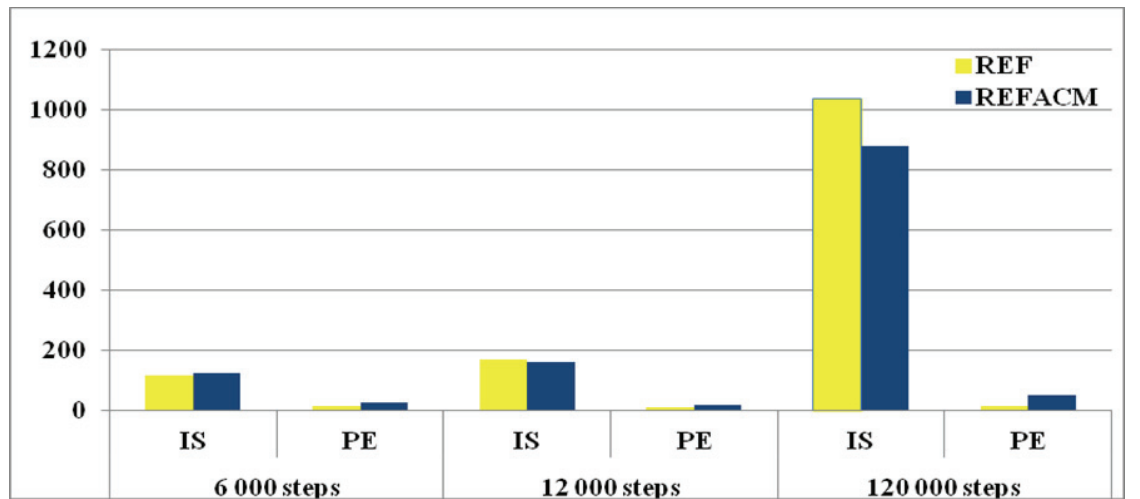

Fig. 1 - Simulation results for REF and REFACM algorithms (lower is better)

\section{CONCLUSTION}

The simulation verification tests featured in the previous section, evaluated in the Matlab Simulink environment confirms that the quality of the tested algorithms is diverse. For long running simulations, the best results are achieved by the REFACM algorithm - which is the focus of this paper. The quality of REFACM in comparison with other algorithms confirms the advantages of using ACM given the specific conditions featured in this work.

The author would like to thank the Slovak Grant Agency APVV for financial support, project ID: APVV-0090-10 and APVV-0160-07. This research is also supported by a grant from Norway through the EEA Financial Mechanism and the Norwegian Financial Mechanism. This project is also co-financed from the state budget of the Slovak Republic. This support is very gratefully acknowledged.

\section{REFERENCES}

[1] SCHMITZ, U., HABER R., BARS R. (2003). A predictive On-Off controller for nonlinear processes. 14th. Int. Conference Process Control 2003, June 8-11, 2003, Strbské Pleso, Slovakia

[2] VACHÁLEK, J. (2004). Priebežná identifikácia laboratórneho modelu s využitím dátového úložiska pre množinu linearizovaných modelov. Proceedings the 6th international scientific-technical conference Process control 2004, ŘíP 2004, 8-11 June 2004, Kouty nad Desnou, Czech republic

[3] KULHAVÝ, R., KRAUS, F.J. (1996). On Duality of regularized Exponencial and Linear Forgetting. Automatica, 1996, vol. 32, No 10, pp. 1403-1415.

[4] PRALY, L. (1993). Robustness of model reference adaptive control. In 3th Yale WorkShop on application of adaptive system theory, 1993, Yale University, USA. 